\title{
Succinate Degradation through the Citric Acid Cycle in Bradyrhizobium japonicum J501 Bacteroids under Low Oxygen Concentrations
}

\author{
Shigeyuki Tajima, Isao Kimura, ${ }^{* *}$ Kiyohiro KouzaI* \\ and Tadasi KASAI \\ Department of Bioresource Science, Faculty of Agriculture, Kagawa University, \\ Miki-cho, Kita-gun, Kagawa 761-07, Japan \\ * Kagawa Prefectural Agricultural Experimental Station, \\ Bushouzan, Takamatsu 761, Japan \\ ** Kagawa Prefectural Fermentation and Foods Experimental Station, \\ Takamatsu Branch, Goutou-chou, Takamatsu 761, Japan
}

Received August 24, 1989

\begin{abstract}
The succinate metabolizing pathway under low oxygen concentrations in soybean nodule bacteroids was surveyed by pulse-chase experiments using $\left[2,3-{ }^{i 4} \mathrm{C}\right]$ succinate and by radiorespirometry. Oxidation of exogenous succinate through the complete citric acid cycle was strongly suggested. Amino acid and sugar formations from exogenous succinate were also observed in the bacteroids.

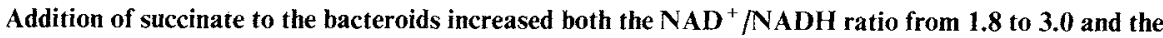
adenylate energy value from 0.25 to 0.53 .
\end{abstract}

$\mathrm{C}_{4}$-dicarboxylic acids, like malic acid or succinic acid, are the most probable in vivo substrates for nodule bacteroids. ${ }^{1,6,12)}$ While it has been shown that cultured Rhizobium has a functional citric acid cycle for the oxidation of $\mathrm{C}_{4}$-dicarboxylic acids, ${ }^{4,7)}$ the nature and control of the cycle in the bacteroids has not been studied well.

When the profiles of the dicarboxylic acid degradation in aerobically isolated nodule bacteroids were analyzed by a radiorespirometric technique under $20 \% \mathrm{O}_{2}$, both the citric acid cycle and glyoxylic acid cycle were suggested to be operative. ${ }^{14)}$ In their experiment, however, the nitrogenase as a major consumer of ATP and the reductant in the bacteroids was inactive because the enzyme system is extremely labile to $\mathrm{O}_{2}$.

We already reported that organic acid degradation in the bacteroids was negligible in $2 \% \mathrm{O}_{2}$, and the incubation system did not accumulate anaerobic metabolites like ethanol or lactic acid under such low oxygen concentrations, ${ }^{16,17)}$ indicating that the bacteroids can metabolize succinate only under oxidative conditions. Addition of Lb, a hemoprotein supporting oxygen transfer in the nodules, to the incubation system restorered the organic acid degrading activity even with such low $\mathrm{O}_{2}$, and in this condition the amount of reduced acetylene (nitrogenase activity) depended on that of added succinate. ${ }^{16)}$

In this experiment the anaerobically isolated bacteroids were pulse-labeled with ${ }^{14} \mathrm{C}$ succinate under the conditions that the nitrogenase system was operating $\left(100 \mu \mathrm{M} \mathrm{LbO}_{2}\right.$ and $2 \% \mathrm{O}_{2} / \mathrm{Ar}$ ), and the fate of ${ }^{14} \mathrm{C}$ was monitored. In addition, radiorespirometry was used to elucidate the pathway for succinate oxidation. Changes in the redox state of $\mathrm{NAD}^{+}$and adenylate energy charge value were also measured to analyze the relationship between carbon metabolism and energy metabolism. 


\section{Materials and Methods}

Biological materials. Soybean seeds were infected with Bradyrhizobium japonicum NIAS J501 and grown in water culture as already described, ${ }^{15)}$ and nodules from 6 - to 7 week-old plants were used for bacteroid and Lb preparations. Both bacteroids and Lb preparations obtained by a series of chromatographies and differential centrifugations, ${ }^{2)}$ respectively, were stored in liquid nitrogen in a Dewar container.

For preparing sample extracts for nucleotide measurement, nodules or roots were crushed in liquid nitrogen immediately after detaching and were ground in a prechilled mortar with a pestle. The powder $(0.5 \mathrm{~g}$ fresh weight) of frozen tissues was used for biochemical assays.

For organic acid measurement the isolated bacteroids were homogenized quickly at $0^{\circ} \mathrm{C}$ with $5 \mathrm{ml}$ of $1 \mathrm{M}$ perchloric acid. The homogenate was mixed with one $\mathrm{ml}$ of $0.1 \mathrm{M}$ Hepes buffer, $\mathrm{pH} 7.5$, and was neutralized carefully with $3 \mathrm{~N} \mathrm{KOH}$ following a centrifugation at $3,000 \times g$ for $10 \mathrm{~min}$. The supernatant was used for organic acid measurement.

Biochemical assays. Citrate, ${ }^{9)}$ 2-oxoglutarate, ${ }^{8}$ succinate $^{20)}$ fumarate, ${ }^{3)}$ and malate ${ }^{21)}$ in bacteroids were measured enzymatically. Elimination of fluorescent compounds in the nodules by a small active charcoal column $(0.7 \times 2 \mathrm{~cm})$ was necessary for the fluorometric assay. Recovery ratios of organic acids from the column were measured by passing through a known amount of organic acids.

$\mathrm{NAD}^{+}$and $\mathrm{NADH}$ in bacteroids were measured by enzymatic cycling methods as Passonneau and Lowry reported. ${ }^{10)}$

AMP, ADP and ATP in bacteroids were measured by HPLC. ${ }^{18)}$

Pulse-chase experiment. The incubation system contained $25 \mu \mathrm{Ci}$ of $\left[2,3-{ }^{14} \mathrm{C}\right]$ succinate, $640 \mathrm{nmol}$ of succinate, and $2 \mu \mathrm{mol}$ of $\mathrm{Lb}$ in $2.5 \mathrm{ml}$ of $10 \mathrm{~mm}$ hepes buffer, $\mathrm{pH} \mathrm{7.0}$. The system was bubbled with $2 \% \mathrm{O}_{2} / \mathrm{Ar}$ for $15 \mathrm{~min}$ at $28^{\circ} \mathrm{C}$, and the gas was introduced into two traps containing monoethanolamine-methanol $(1: 1, \mathrm{v} / \mathrm{v})$ solution. To eliminate the effects of $\mathrm{NH}_{3}$ that might be accumulated during the incubation and inhibit ATP formation, $\mathrm{O}_{2} / \mathrm{Ar}$ was used instead of $\mathrm{O}_{2} / \mathrm{N}_{2}$. The reaction was started by injecting the bacteroid suspension $(100 \mathrm{mg}$ bacteroids in $1.5 \mathrm{ml}$ hepes buffer $\mathrm{pH} 7.0$ ) through a serum rubber septum. After 5 min of incubation with ${ }^{14} \mathrm{C}$-succinate, the incubation system was changed to that of cold succinate by centrifugation $(10,000 \times g, 5 \mathrm{~min})$. Air-tight centrifuge tubes were used to keep low oxygen tension in the buffer system, and it took $15 \mathrm{~min}$ at $4^{\circ} \mathrm{C}$ to change the incubation system. Then the chase treatment was started by incubating the suspension again in the same conditions as described above except the substrate was cold succinate. Every $10 \mathrm{~min}$, one $\mathrm{ml}$ of the suspension and $0.1 \mathrm{ml}$ of the ethanolamine solution in the two traps were collected and were used for biochemical and radioactive assays.

For fractionations of bacteroid extract, the method of Redgwell ${ }^{11}$ was basically used, except that keto acids in the organic acid fraction were measured after converting those to corresponding amino acids. ${ }^{19}$ )

For separating organic acids by HPLC an anion exchange resin column $(0.46 \times 25 \mathrm{~cm})$ packed with $\mathrm{MCI}$ gel CDR-10 (Cl-form, Mitsubishi Kasei Co.) was used. The column was eluted with $0.15 \mathrm{M} \mathrm{NaCl}$ (adjusted the $\mathrm{pH}$ to 3.1 with phosphoric acid) at $55^{\circ} \mathrm{C}$, and major organic acids of citric acid cycle were separated in $30 \mathrm{~min}^{17)}$

Sugars were separated by HPLC with a CK08S column $\left(\mathrm{H}^{+}\right.$-form, $\left.0.8 \times 25 \mathrm{~cm}\right)$ and with CDR-10 column (borateform, $0.46 \times 25 \mathrm{~cm}$ ). Sample fractions were put onto the CK08S column, and the column was eluted with water at room temperature resulting in separation by molecular weight. Further separations of the disaccharide fractions that were separated by CK08S column were done with a CDR-10 (borate form) column by eluting with $0.2 \mathrm{M}$ borate buffer, $\mathrm{pH} 9.0$, at $55^{\circ} \mathrm{C}$.

Radiorespirometric experiment The apparatus for the reaction system was basically that of the Pulse-chase experiment, and $5 \mathrm{ml}$ of $20 \mathrm{~mm}$ Hepes buffer $\mathrm{pH} 6.5$ containing $600 \mathrm{nmol}$ of Lb, $2.4 \mu \mathrm{mol}$ of succinate, and $0.5 \mu \mathrm{Ci}$ of various ${ }^{14} \mathrm{C}$-organic acids was bubbled continously with $2 \% \mathrm{O}_{2} / \mathrm{Ar}$ at $30^{\circ} \mathrm{C}$ for $15 \mathrm{~min}$. The bacteroid suspension ( $50 \mathrm{mg}$ dry weight $/ \mathrm{ml} 20 \mathrm{~mm}$ Hepes buffer, $\mathrm{pH}$ 6.8) were then injected into the incubation system, and the reaction was started to trap the released ${ }^{14} \mathrm{CO}_{2}$. Every $10 \mathrm{~min} 100 \mu \mathrm{l}$ of the solution in the traps was collected and the radioactivity was measured.

\section{Results}

During the pulse-labeling period, approximately $0.25 \mu \mathrm{Ci}$ of ${ }^{14} \mathrm{C}$ (about $1 \%$ of total ${ }^{14} \mathrm{C}$-succinate in the incubation system) was incorporated into the bacteroids, and after centrifugation to change the incubation system to that for chase treatment, the radioactivity in the supernatant decreased to $2.4 \%$ of the initial value (Fig. 1). $\mathrm{No}^{14} \mathrm{CO}_{2}$ was released during the pulse $(5 \mathrm{~min})$ and the following centrifugation $(15 \mathrm{~min})$ periods, and this stalling of respiration was suggested to be due to the low temperature $\left(4^{\circ} \mathrm{C}\right)$ during the centrifugation. ${ }^{14} \mathrm{CO}_{2}$ release started at the beginning of the chase treatment, and $40 \%$ of the ${ }^{14} \mathrm{C}$ in the incubation system was recovered as ${ }^{14} \mathrm{CO}_{2}$ in $30 \mathrm{~min}$. Though the ${ }^{14} \mathrm{C}$ content in the bacteroids decreased bery slowly, the decrease of 


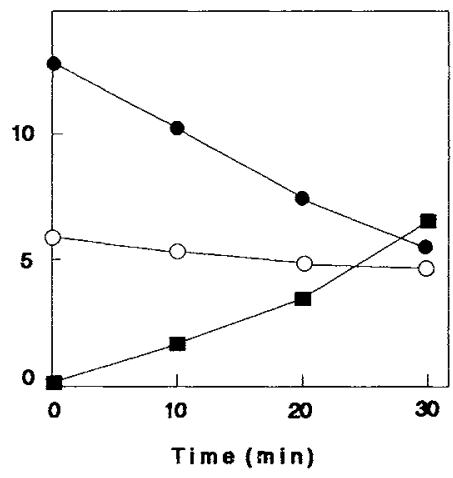

Fig. 1. Distribution of ${ }^{14} \mathrm{C}$ among Supernatant Bacteroids $(\bigcirc)$, and ${ }^{14} \mathrm{CO}_{2}(\square)$ Fractions during the Chase Treatment.

The incubation was started by addition of the bacteroids to the incubation system with cold succinate.

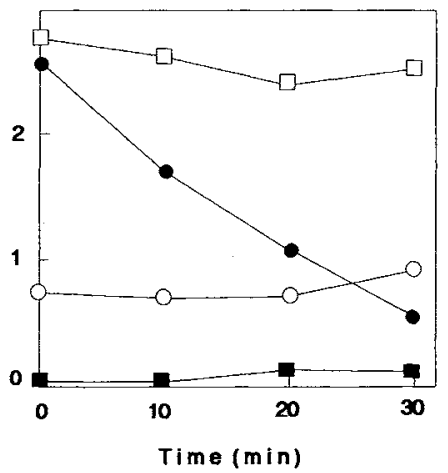

Fig. 2. Distribution of ${ }^{14} \mathrm{C}$ among Amino Acid ( $\left.\square\right)$, Organic Acid (O), Keto Acid ( $\mathbf{a}$ ), and Neutral (O) Fractions during the Chase Treatment.

The incubation was started by addition of the bacteroids to the incubation system with cold succinate.

${ }^{14} \mathrm{C}$ in the supernatant was mainly recovered in the $\mathrm{CO}_{2}$ fraction.

When the bacteroids were fractionated to amino acids, organic acids, keto acids, and neutral fractions, only the organic acid fraction decreased it's radioactivity rapidly during the chase (Fig. 2). Other amino acid and neutral fractions kept their radioactivities after spontaneous incorporation of ${ }^{14} \mathrm{C}$ into those fractions at the beginning of the incubation (Fig. 2). The keto acid fraction contained negligible radioactivity.

When the organic acid fraction was analyzed by HPLC, ${ }^{14} \mathrm{C}$ was mainly localized in

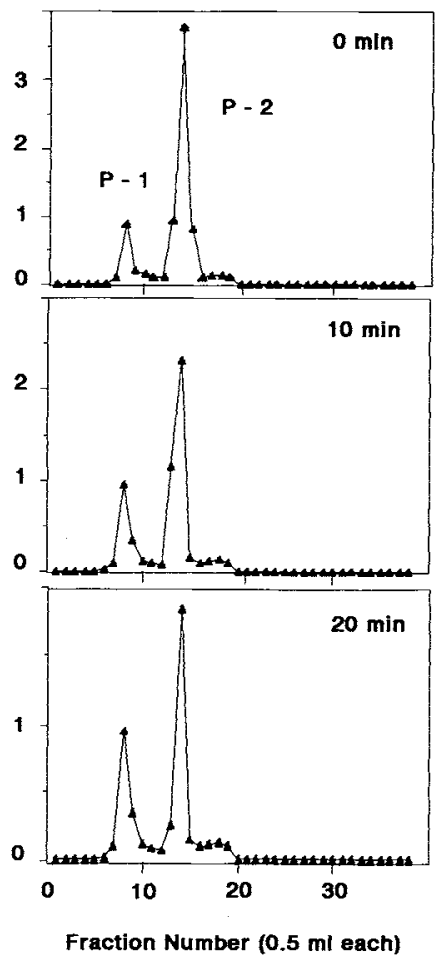

Fig. 3. Separation of ${ }^{14} \mathrm{C}$ in the Organic Acid Fraction of the Bacteroids at Various Incubation Times by HPLC.

Succinate, malate, citrate, fumarate, and 2-oxoglutarate were eluted at fraction numbers 13, 15, 28, 39, and 43, respectively.

two peaks (P-1 and P-2) at all the incubation times (Fig. 3). The retention times of the peaks corresponded to those of sugar acids like glucuronic acid and of succinate + malate.

When the first peak of ${ }^{14} \mathrm{C}$ (Fig. 3, P-1) was passed through a Sephadex G-25 column $(1.2 \times 20 \mathrm{~cm})$ the radioactivity eluted at the void volume. The radioactive fractions were pooled, passed through a SP-Sephadex column, and hydrolyzed with conc $\mathrm{H}_{2} \mathrm{SO}_{4}\left(90^{\circ} \mathrm{C}\right.$, $30 \mathrm{~min}$ ) after condensing in vacuo. When the hydrolysate was put on a Sephadex G-25 column again, the elution pattern of radioactive fractions was of low molecular weight compounds. HPLC analysis with a cation exchange column (MCI gel CK08S, Mitsubishi Kasei Co.) of the hydrolysate showed the elution position of ${ }^{14} \mathrm{C}$ was not of crotonic acid (monomer of poly- $\beta$-hydroxybutyrate), but was of monosaccharides like glucuronic acid 
(data not shown). This detail is under investigation in our laboratory.

Rechromatography of the second ${ }^{14} \mathrm{C}$ peak (P-2) at $20 \mathrm{~min}$ showed that $90 \%$ of the ${ }^{14} \mathrm{C}$ was of succinate and another $10 \%$ was of malate. Similar data were obtained at 30,40 , an $50 \mathrm{~min}$. Figure 3 also showed that negligible radioactivities were accumulated in other organic acids of the citric acid cycle. No ${ }^{14} \mathrm{C}$ ethanol or ${ }^{14} \mathrm{C}$-lactic acid was detected.

The neutral fractions of each incubation time were pooled, condensed, and analyzed by HPLC with a CK08S column (H-form). In all incubation times ${ }^{14} \mathrm{C}$ in the neutral fraction was eluted as one peak, and the elution position was of neutral disaccharides like maltose or sucrose. When the radioactive eluates from the CK08S column were pooled, condensed, and analysed with a CDR-10 column (borate form) as described in Materials and Methods, ${ }^{14} \mathrm{C}$ was eluted as one peak and the elution position corresponded to that of maltose (data not shown).

When the changes in pool sizes of citrate, 2-oxoglutarate, succinate, fumarate, and malate in the bacteroids incubated under the same conditions as in the chase experiment were measured, those major organic acid contents did not change extensively except for succinate during the incubation (Table I). After $10 \mathrm{~min}$ of incubation the succinate, fumarate, and citrate pools showed almost constant values.

Table I. Changes in Various Organic Acid CONTENTS DURING THE INCUBATION WITH Exogenous Succinate

\begin{tabular}{lrrrr}
\hline \multirow{2}{*}{$\begin{array}{c}\text { Organic acid } \\
\text { assayed }\end{array}$} & \multicolumn{4}{c}{ Chase incubation time (min) } \\
\cline { 2 - 5 } & Control & 0.5 & 10 & 20 \\
\hline & & & & \\
Citrate & 110 & 56 & 66 & 77 \\
2-Oxoglutarate & 87 & 56 & 68 & 22 \\
Succinate & 170 & 490 & 170 & 160 \\
Fumarate & 38 & 70 & 130 & 110 \\
Malate & 350 & 520 & 660 & 590 \\
\end{tabular}

The values (nmol/dry weight gram) were expressed as means of duplicate assays. As the control the bacteroids were injected into the incubation system containing $0.5 \mathrm{M}$ PCA.
These data show the bacteroids can synthesize amino acids and sugars from succinate. The presence of almost all the ${ }^{14} \mathrm{C}$ in succinate (P-2), though the flow of ${ }^{14} \mathrm{C}$ from ${ }^{14} \mathrm{C}$-succinate to ${ }^{14} \mathrm{CO}_{2}$ was vigorous, suggested that the metabolically active organic acid pool was small and separated from the large inactive one in the bacteroids.

Since the ${ }^{14} \mathrm{C}$ content in major organic acids of citric acid cycle was too small to trace the metabolic pathway (Fig. 3), radiorespirometric technique was used. Figure 4 a compares the ${ }^{14} \mathrm{CO}_{2}$ formation rate from $\left[1,4-{ }^{14} \mathrm{C}\right]$ succinate and that from $\left[2,3-{ }^{14} \mathrm{C}\right]$ succinate. Figure $4 \mathrm{~b}$ also compares the values from $\left[1-{ }^{14} \mathrm{C}\right]$ acetate and from $\left[2-{ }^{14} \mathrm{C}\right]$ acetate. Both clearly showed ${ }^{14} \mathrm{C}$ in carboxyl groups was incorporated into $\mathrm{CO}_{2}$ much faster than ${ }^{14} \mathrm{C}$ in methylene groups, supporting the citric acid cycle operation in bacteroids. In addition, fluoroacetate (the precursor of fluorocitrate as a inhibitor of isocitrate dehydrogenase, $0.5 \mathrm{~mm}$ ) and malonate (an inhibitor of succinate dehydrogenase, $5 \mathrm{~mm}$ ) in the incubation system decreased ${ }^{14} \mathrm{CO}_{2}$ formation as shown in Fig. 5a

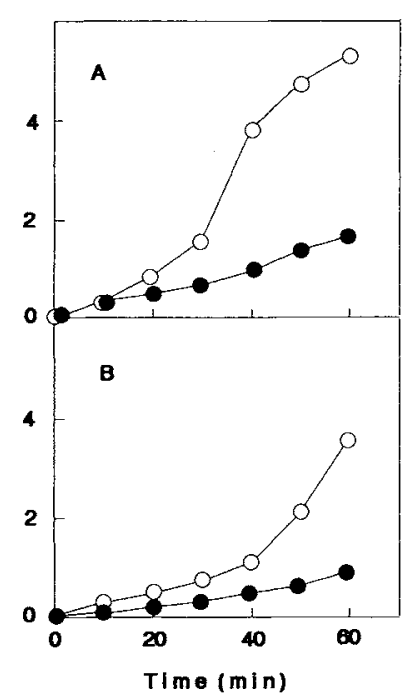

Fig. 4. Evolution of ${ }^{14} \mathrm{CO}_{2}$ from Various ${ }^{14} \mathrm{C}$-Organic Acids.

The incubation was started in Fig. $4 \mathrm{a}$ by the injection of $0.5 \mu \mathrm{Ci}$ of $\left[1,4-{ }^{14} \mathrm{C}\right]$ succinate $(\mathrm{O})$ and $\left[2,3-{ }^{14} \mathrm{C}\right]$ succinate (-), and in Fig. $4 \mathrm{~b}$ by the injection of $0.5 \mu \mathrm{Ci}$ of [1$\left.{ }^{14} \mathrm{C}\right]$ acetate $(\mathrm{O})$ and $\left[2 \cdot{ }^{14} \mathrm{C}\right]$ acetate 


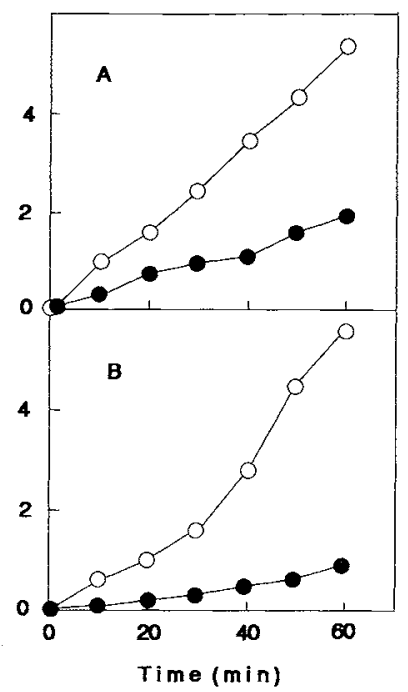

Fig. 5. Effects of Various Metabolic Inhibitors on Evolution of ${ }^{14} \mathrm{CO}_{2}$ from ${ }^{14} \mathrm{C}$-Organic Acids.

The incubation was started in Fig. $5 \mathrm{a}$ by the injection of $0.5 \mu \mathrm{Ci}$ of $\left[1,4-{ }^{14} \mathrm{C}\right]$ succinate $(\mathrm{O})$ and $\left[1,4-{ }^{14} \mathrm{C}\right]$ succinate $+0.5 \mathrm{~mm}$ fluoroacetate (O), and in Fig. $5 \mathrm{~b}$ by the injection of $0.5 \mu \mathrm{Ci}$ of $\left[1,4^{14} \mathrm{C}\right]$ succinate $(O)$ and $[1,4-$ ${ }^{14} \mathrm{C}$ ]succinate $+5 \mathrm{~mm}$ malonate (

Table II. Changes in the Redox States of Pyridine and Adenine NuCleotides during InCUBation with Exogeneous Succinate

\begin{tabular}{lcccccc}
\hline & \multicolumn{5}{c}{ Chase incubation time (min) } \\
\cline { 2 - 6 } & Control & 0.5 & 10 & 20 & 30 \\
\hline $\mathrm{NAD}^{+}$ & 201 & - & 249 & 159 & 192 \\
$\mathrm{NADH}^{+}$ & 110 & - & 82 & 72 & 84 \\
$\mathrm{NAD}^{+} / \mathrm{NADH}$ & 1.8 & - & 3.0 & 2.2 & 2.3 \\
Energy charge & 0.25 & 0.53 & 0.29 & 0.30 & 0.33 \\
\hline
\end{tabular}

The values (nmol/dry weight gram) were expressed as means of duplicate assays. As the control the bacteroids were injected into the incubation system containing $0.5 \mathrm{M}$ PCA.

and $5 \mathrm{~b}$. The data supported the idea of the contribution of citric acid cycle enzyme activities for ${ }^{14} \mathrm{CO}_{2}$ formation in the bacteroids.

Changes in the redox state of $\mathrm{NAD}^{+}$and $A E C$ values were analyzed during the incubation under the same condition to the chase experiment. Table II shows that the $\mathrm{NAD}^{+} / \mathrm{NADH}$ ratios of the stored bacteroids (control) was 1.8. The value increased to 3.0 just after the bacteroids were injected into the incubation system, and then the values stayed around 2.2

The AEC value of isolated bacteroids was 0.25 , at the $0.5 \mathrm{~min}$ of incubation the value increased to 0.53 , and then went down to 0.29 , followed by a gradual increase to 0.33 (Table II).

\section{Discussion}

Figure 1 shows that the bacteroids actively metabolized $40 \%$ of total $\left[2,3-{ }^{14} \mathrm{C}\right]$ succinate in the incubation system to ${ }^{14} \mathrm{CO}_{2}$ during the chase treatment $(30 \mathrm{~min})$. Though ${ }^{14} \mathrm{C}$-amino acids and ${ }^{14} \mathrm{C}$-sugars were spontaniously synthesized from the ${ }^{14} \mathrm{C}$-succinate added, radioactivities in those fractions kept their initial values during the incubation, suggesting that the metabolism of those compounds in the bacteroids shifted to their synthesis. Only the organic acid fraction decreased its specific radioactivity linearly with time (Fig. 2 and Table I), indicating the exogenous [2,3${ }^{14} \mathrm{C}$ ]succinate was converted to ${ }^{14} \mathrm{CO}_{2}$ mainly through the organic acid fraction in the bacteroids. Recently Kahn et al., ${ }^{5)}$ Yoneyama, ${ }^{22)}$ and Kouchi ${ }^{6)}$ reported that exogenous amino acids could support both the bacteroids' respiration and acetylene reduction activities. Figure 2, however, showed that the amino acids formed in the bacteroids were not used as respiratory substrates in our case. Since the incubation system in Fig. 2 was bubbled with continous $\mathrm{O}_{2} / \mathrm{Ar}$, the ${ }^{14} \mathrm{C}$-amino acid formed would be due to endogenous $\mathrm{NH}_{4}^{+}$that was accumulated in the bacteroids and the concentration might be too small for the enzymes responsible for amino acid catabolism.

When ${ }^{14} \mathrm{C}$ accumulation in various organic acids was analyzed by HPLC, only two ${ }^{14} \mathrm{C}$ peaks were detected (Fig. 3), and they were suggested to be a polymer of sugar-acid (P-1) and succinate + malate (P-2). Since about $80 \%$ of the ${ }^{14} \mathrm{C}$ in $\mathrm{P}-2$ was of succinate and the radioactivity of $\mathrm{P}-2$ decreased during the incubation time with a constant ratio between succinate and malate, ${ }^{14} \mathrm{C}$ contents in organic 
acids of the citric acid cycle except succinate and malate were suggested to be too low to calculate their specific radioactivity. Though the ${ }^{14} \mathrm{C}$ flow from exogenous succinate to $\mathrm{CO}_{2}$ was vigorous and the organic acids pool sizes of citric acid cycle in the bacteroids did not change much during the incubation time (Table I), ${ }^{14} \mathrm{C}$ contents in major organic acids of citric acid cycle did not increased enough to be detected (less than $1 \%$ of ${ }^{14} \mathrm{C}$ content of succinate fraction). Only when the bacteroids were incubated with large amounts of ${ }^{14} \mathrm{C}$ succinate continuously, incorporation of ${ }^{14} \mathrm{C}$ into 2-oxoglutarate and other organic acids was observed after the acids were separated by HPLC. ${ }^{17)}$ Our working conclusion was that the active pools of organic acids in the bacteroids were small and separated from large inactive ones. A relatively small ${ }^{14} \mathrm{C}$-organic acid pool in the bacteroids was observed even when exogenous ${ }^{14} \mathrm{C}$-succinate was supplied to the bacteroids continously, ${ }^{177}$ and the data also supported this conclusion. Similar result was obtained from the constant-ratio isotope experiment with intact soybean nodules by Kouchi et al., ${ }^{6}$ though the mechanism for the compartmentation of metabolic pools were obscure.

Though the pulse-chase experiment failed to indicate the succinate metabolizing pathway, no accumulation of ${ }^{14} \mathrm{C}$-ethanol, ${ }^{14} \mathrm{C}$-lactate or ${ }^{14} \mathrm{C}$-pyruvate from $\left[2,3-{ }^{14} \mathrm{C}\right]$ succinate indicated negligible anaerobic metabolism in the bacteroids and suggested the operation of citric acid cycle (Fig. 3).

Further experiments to analyze the oxidation of exogenous succinate through the citric acid cycle in the bacteroids were done by a radio-respirometric technique. Figure $4 \mathrm{a}$ indicated that the methylene carbons of succinate were introduced into $\mathrm{CO}_{2}$ much more slowly than carboxyl carbons, and Fig. $4 \mathrm{~b}$ showed a similar result for acetate. Inhibitors of aconitase (fluoroacetate) and of succinate dehydrogenase (malonate) depressed ${ }^{14} \mathrm{CO}_{2}$ formation from $\left[1,4-{ }^{14} \mathrm{C}\right]$ succinate. All these data supported the oxidative degradation of succinate through citric acid cycle in the bac- teroids even under $2 \%$ oxygen. Operation of glyoxylic acid cycle in the bacteroids was reported, ${ }^{14)}$ but Fig. $4 \mathrm{~b}$ shows the contribution of glyoxylic acid cycle was minor though the bacteroids can form ${ }^{14} \mathrm{CO}_{2}$ from $\left[1-{ }^{14} \mathrm{C}\right] \mathrm{gly}$ oxylate (data not shown).

HPLC analysis of the neutral fraction of the bacteroids strongly suggested that the ${ }^{14} \mathrm{C}$ in $\left[2,3-{ }^{14} \mathrm{C}\right]$ succinate was incorporated into a disaccharide. Elution profiles of the compound were not of trehalose, but of meltose. Maltose was already reported in the bacteroids though trehalose formation in the bacteroids was more extensive. ${ }^{12,13)}$

When succinate oxidation in the bacteroids through citric acid cycle are vigorous, NADH and reductant generated must be reoxidized immediately for continuous operation of the cycle. Table II shows the presence of an active NADH-oxidizing system in the bacteroids since the endogenous NADH content decreased even after the addition of succinate to the incubation system. Nodule and root tissues showed higher $\mathrm{NAD}^{+} / \mathrm{NADH}$ ratios $(12$ and 5.3 respectively, ${ }^{18}$ and the rather low value of bacteroids were suggested to be a characteristic of bacteroid energy metabolism. The adenylate energy charge value in the bacteroids responded to succinate addition to the incubation system (Table 2). In $0.5 \mathrm{~min}$ the value increased from 0.25 to 0.53 , then depressed to 0.29 , followed by a gradual increase to 0.33 in $30 \mathrm{~min}$. In this case, the incubation system contained no nitrogen and the nitrogenase system would be operating to generate hydrogen from water.

Acknowledgment. This work is supported by a Grantin-Aid for Scientific Research from the Ministry of Agriculture, Forestry and Fisheries of Japan (BMP-89-VI-2).

\section{References}

1) F. J. Bergersen and G. L. Turner, J. Gen. Microbiol., 91, 345 (1975).

2) D. W. Emerich, T. R. Argueso, T. M. Ching and H. J. Evans, J. Bacteriol., 137, 153 (1979).

3) N. D. Goldberg and J. V. Passonneau, in "Methods of Enzymatic Analysis," 2nd Ed., ed. by F. J. 
Bergmeyer, Verlag Chemie Gmbh Weinheim, Academic Press, 1982, p. 160.

4) B. B. Keele, P. B. Jr. Hamilton and G. H. Elkan, J. Bacteriol., 97, 1184 (1970).

5) M. L. Kahn, J. Kraus and J. E. Somerville, "Nitrogen Fixation Research Progress," MartinusNijhoff Publ. Dordrecht, 1985, pp. 193-199.

6) H. Kouchi and T. Yoneyama, Physiol. Plant., 68, 238 (1986).

7) K. Mulongoy and G. H. Elkan, J. Bacteriol., 131 , 179 (1977).

8) R. G. Narins and J. V. Passonneau, in "Methods of Enzymatic Analysis," 2nd Ed., ed. by F. J. Bergmeyer, Verlag Chemie Gmbh Weinheim, Academic Press, 1982, p. 1580.

9) J. V. Passonneau and J. G. Brown, in "Methods of Enzymatic Analysis," 2nd Ed., ed. by F. J. Bergmeyer, Verlag Chemie Gmbh Weinheim, Academic Press, 1982, p. 1565.

10) J. V. Passonneau and O. H. Lowry, in "Methods of Enzymatic Analysis," 2nd Ed., ed. by F. J. Bergmeyer, Verlag Chemie Weinheim, Academic Press, 1982, pp. 2059-2077

11) R. J. Redgwell, Anal. Biochem., 107, 44 (1980).
12) J. G. Streeter and S. O. Salminen, in "Nitrogen Fixation Research Progress," ed. by H. J. Evans, Martinus Nijhoff Publishers, 1984, p. 277.

13) J. G. Streeter, Plant Physiol., 85, 768 (1987).

14) I. Stovall and M. Cole, Plant Physiol., 61, 787 (1978).

15) S. Tajima and Y. Yamamoto, Plant Cell Physiol., 18, 247 (1977).

16) S. Tajima, H. Sasahara, H. Kouchi, T. Yoneyama and J. Ishizuka, Agric. Biol. Chem., 49, 3473 (1985).

17) S. Tajima, I. Kimura and H. Sasahara, Agric. Biol. Chem., 50, 1009 (1986).

18) S. Tajima and K. Kouzai, Plant Cell Physiol., 30, 589 (1989).

19) Y. Tokumitu and M. Ui, Anal. Biochem., 59, 110 (1974).

20) J. R. Williamson, in "Methods of Enzymatic Analysis," 2nd Ed., ed. by F. J. Bergmeyer, Verlag Chemie Gmbh Weinheim, Academic Press, p. 1616.

21) I. Witt, in "Methods of Enzymatic Analysis," 2nd Ed., ed. by F. J. Bergmeyer, Verlag Chemie Gmbh Weinheim, Academic Press, p. 1593.

22) T. Yoneyama, J. K. Lahda and I. Watanabe, J. Plant Physiol., 127, 251 (1988). 